\title{
Peculiarities of development of digital financial ecosystem
}

\author{
Aleksandr Almosov ${ }^{1}$, Svetlana Bondareva ${ }^{2 *}$, Oksana Darelina ${ }^{3}$, Sofya Potomova $^{4}$ and Elena Timacheva ${ }^{5}$ \\ ${ }^{1}$ Russian Presidential Academy of National Economy and Public Administration, Volgograd Institute of Management, Gagarina \\ Street, 8, Volgograd, vsamol@yandex.ru \\ ${ }^{2}$ Russian Presidential Academy of National Economy and Public Administration, Volgograd Institute of Management, \\ Gagarina Street, 8, Volgograd, s.a.bondareva@mail.ru \\ ${ }^{3}$ Russian Presidential Academy of National Economy and Public Administration, Volgograd Institute of Management, \\ Gagarina Street, 8, Volgograd, darelina@yandex.ru \\ ${ }^{4}$ Russian Presidential Academy of National Economy and Public Administration, Volgograd Institute of Management, \\ Gagarina Street, 8, Volgograd, potomova@inbox.ru \\ ${ }^{5}$ Russian Presidential Academy of National Economy and Public Administration, Volgograd Institute of Management, \\ Gagarina Street, 8, Volgograd, borisova_e@mail.ru
}

\begin{abstract}
The development of information society based on creating digital information channels fosters the expansion of virtual interaction of the participants of social relations. It gives rise to technological transformation of financial infrastructure and fosters related changes in other spheres of economy and social life. This research is aimed at finding out peculiarities of forming and developing digital financial microsystems and determining possible scenarios of the development of the Russian national financial ecosystem. The analysis of the statistical data has shown that developing digital technologies leads to the transformation of financial services consumer behaviour. They move from off-line environment with cash payments to the on-line service with non-cash settlements predominance and distant interaction. The trust in fintech-companies and digital financial services is constantly increasing. The caried-out analysis has shown that digitalization of financial sector increases its financial accessibility and fosters poverty reduction (Wang ,Yang, Chiu \& Lin, 2020) and provides economic growth (Siddik \& Kabiraj, 2020). It forms the basis for the transformation of financial architecture and the expansion of digital financial ecosystems in Russia. On the basis of world experience as well as Russian practice, the authors determined the elements and principles of digital financial ecosystem development, identified types of forming and levels of ecosystems functioning. The authors considered two variants of forming the national digital financial ecosystem that differ in the form of interaction of state and private ecosystems functioning. The authors considered two variants of forming the national digital financial ecosystem that differ in the form of interaction of state and private ecosystems. The obtained conclusions are important for making project decisions by the authorities, financial organizations and technological companies.
\end{abstract}

\section{Introduction}

At present country's competitiveness and economic development are mostly determined by the level of economy digitalization. The new institutional environment is being formed, so called digital environment. It is based on the transformation of the information and channels of its transmission into digital form that fosters the expansion of virtual interaction of social relations participants.

Dynamic development of new technologies and their penetration in all spheres of human activity served as the driver of the digital transformation of institutional environment. It served as the driving force for fast fundamental changes in world economy and structural industrial reorientation. Such large-scale changes were interpreted as the fourth industrial revolution - Industry 4.0.

Simultaneous significant changes in social sphere are based on the reassessment of social values. Contemporary generation actively uses new technologies creating permanent demand for innovative personalized goods, services and technologies. These conditions cause the development of economic sharing at the same time the market is becoming the subject to mass personalization. It implies that human activity on the one hand is adapted to technological changes and on the other hand differences in individual preferences are the source of current changes.

\footnotetext{
* Corresponding author: s.a.bondareva@mail.ru
} 
Thus, new industrial environment implies forming a digital ecosystem by means of digitalization of all physical assets, information and financial resources aimed at integration of the participants of economic relations into digital space for interaction, decision making and regulating. These trends influence the development of the financial sector.

\section{Problem Statement}

Technological transformation of financial infrastructure initiates and fosters related changes in other spheres of economy and social life. Development of digital technologies leads to the transformation of behaviour of financial services consumers. They move from off-line environment with cash payments to on-line service with predominance of non-cash settlements with distant interaction. This tendency can be observed in Russia in the context of transactions by means of payment cards. Over the last decade the share of "card transactions" related to payment for goods and services has almost tripled reaching $91 \%$ in the total volume of card transactions. At that the number of card transactions has increased over 10 times mostly due to their use for paying for goods and services (Figure1).

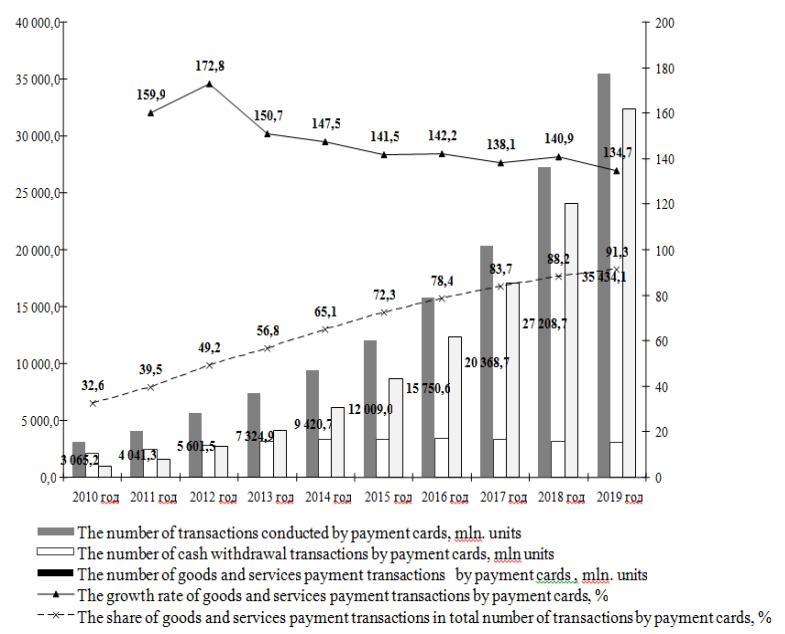

Fig. 1. Dynamics and structure of card transactions in Russia over the period 2010-2019.

The Source: Bank of Russia

Gradual refusal from cash is caused by the development of payment infrastructure, increasing financial literacy of the population and penetration of digitalization in all spheres of activity. According to the research made by National Agency for Financial Studies over a half of Russians (56\%) use online banking. In 2020 the share of users of mobile banking has increased up to $51 \%$ (in $2018-26 \%$ ) [1]. The experts point to a rather high level of digital technologies penetration into the Russian financial market [2].

One of the determinants of the structural changes in the financial sector is changing consumers' trust. The demand for traditional banking service is reducing among young generation that actively consumes services and goods of technological companies. As it has been shown by the researchers the consumers of the platform products Apple, Amazon, Alibaba will agree to receive banking services from these companies (if they provided them) hoping to get a related level of service [3]. In many respects it can be explained by increasing digital financial literacy of the population, forming skills of online interaction, scales of using and expanding of smartphones' functionality, developing e-commerce.

\section{Research Questions}

This research is aimed at answering the following questions:

1.How does the banking sector change in the context of digital expansion?

2. What elements does digital financial ecosystem include?

3. What principles are fundamental for forming and developing digital financial ecosystem?

4. What types of digital financial ecosystems exist?

5. What variants of development of Russian national digital financial ecosystem are possible?

\section{Purpose of the Study}

The relevance of the study is determined by the fact that digital financing and providing financial accessibility aimed at poverty reduction and economic growth are becoming high priorities of the governmental, business and scientific focus. In this respect the authors set the goal to study peculiarities of forming and developing ecosystem as the form of interaction in digital environment and expanding financial accessibility. In order to reach the set goal the following objectives were set and achieved; we studied the factors of digitalization; considered the factors of digitalization of financial services; found out advantages of digital mode of interaction in the financial market; researched the models of creating digital banks; identified elements of digital financial ecosystem and principles of its development; characterized different types of digital financial ecosystems; predicted scenarios of development of Russian national financial ecosystem.

\section{Research Methods}

Methodology of the research is determined by the complexity and diversity of the challenges met that requires using different methods and tools. The present research has been conducted by means of integrating forms, methods and logical operations of the research, using analyses and synthesis abstraction and concretization comparison, generalization and systematization, methods of descriptive statistics and statistical analysis, data analysis and interpretation in graphs and figures.

\section{Findings}

In conditions of increasing demand in the market on-line service is being developed, digital financial innovations 
including digital financial products, digital channels and business-models are introduced, As a result digitalization of financial relations can be observed: increasing use of digital financial innovations along with the consuming of financial services and managing financial resources.

New technologies in financial sphere can provide accessibility, effectiveness and safety of the services rendered, increase intuitive ability of services, decrease transaction costs. Platform solutions for digital transactions can be used by users with different levels of income without any time and territory restrictions. Digital financial services significantly reduce transaction costs, raise effectiveness of risk-oriented pricing and risk management, reduce information asymmetry, expand the range of financial products and increase transparency of activity of financial organizations as well as consumers of financial services. In addition using technological innovations in inclusive financing give rise to competition between financial organizations that fosters quality improving and reducing the cost of financial goods and services [4].

Creating new models of expanding financial services (external agent networks, banks without the network of branches), new opportunities for consumers' access and personal online control are some of the directions of developing the financial sector which is still in the process of constant innovation search and adaptation. The phenomenon of financial technologies has created new opportunities for financial organizations as well as for consumers of financial services. on the basis of speed, flexibility, accessibility and diversity.

Financial innovations have a significant impact on sustainable development and can be considered as an instrument for economic integration [5]. Mobile payments play a vital role in promoting financial accessibility and are important instruments providing the growth of the standard of life even among the disadvantaged population [6]. At the same time the researches prove that developing financial technologies is significantly dependent on the growth of economy and opportunities of the financial sector [7].

In current conditions banks actively implement technological service novelties and develop online and mobile banking trying to save their positions in the market. However, renewing the old-fashioned ITinfrastructure of a classical bank and meeting all the requirements of the regulating authority demand significant costs that in its turn is reflected on the cost of services. The practice shows that the fastest and the most costless project is launching start-ups of fintechcompanies or digital banks (neobanks).

1. Developing by the classical bank additional digital brand. Such model was used by Singapore bank OCBC having established FRANK, by Spanish CaixaBank having established LKXZ, Financial corporation "Otkrytie" having established Roketbank and Tochka Bank.

2. Using a digital channel for resaling traditional banking products on the platform of the company independent from the bank. The examples of such model are Simple (USA), Moven (USA), Talkbank (Russia).
3. Creating of social digital financial organization as subcompany of a classical bank. This variant was chosen for example for creating Hello Bank (subcompany of French BNP Paribas) and Touchbank (included in the financial group OTP Group).

4. Creating initially independent digital bank using only digital channels of service, the pattern of Fidor Bank (Germany), Tangerine (Canada), Tinkoff Bank (Russia), Modulbank (Russia).

5. Creating neobank by a popular fintech-company for making additional profit by means of using payment services and financial platforms with a wide client base. Such practice can be observed in the activity of the companies dealing with e-commerce (Amazon, Alibaba), mobile communication (Megafon), software providing (Apple).

It should be noted that development of any digital ecosystem is determined by the extent of integration of financial technologies. It can be explained by the fact that modern economy is significantly "financialized" [8] and differs by its high level of monetization of social relations and BigData. In modern ecosystem financial technologies are a compulsory component, consequently the ecosystem based on the combination of digitalization and financed should be considered as a digital financial system.

Digital financial ecosystem is a whole complex of interrelated elements of organization of functional and institutional financial interrelations of economic subjects. Its creation can be initiated by some economic subjects: state structures (governmental authorities, central bank, institutions), business-structures (fintechcompanies, banks, corporations), non-commercial organizations, communities and social groups. Financial ecosystem plays a pivotal role in allocation of capital, reaching an agreement by depositors and investors that is especially important in case of limited sources of financing [9]. However, it should be noted that often financial services and applications are taken by the consumers for granted and don't appear to be a competitive advantage and don't foster the inflow of new participants into the ecosystem.

The world experience shows that without providing conditions for development of finances at nanoeconomic level it is impossible to provide sustainable rates of economic growth. Digital financial ecosystems facilitate realization of resource potential of population in economy that is made up by human capital, entrepreneurial activity, and personal investments [10].

A digital financial system is developed on the basis of a number of principles.

"One stop-one-shop principle" which characterizes the ecosystem as a specific integral complex where all necessary things for comprehensive functioning of economic subjects are concentrated in one place. This principle facilitates satisfying different individual needs by means of one online resource (multifunctional digital platform). The services and applications can be provided by the developer of the digital platform as well as integrated by other partner companies. On the basis of mutually favourable cooperation the ecosystem accumulates financial (in the first turn payment) services 
as well as Internet-trade services, public services, social interaction, research and obtaining information and etc.

The principle of mutually favourable cooperation («win-win» principle) implies that all participants of the ecosystem get a positive effect as e result of their interaction. The owner besides direct economic effect (profit growth and costs reducing) has an opportunity to get additional information about participants which enables him to improve a business-model of the ecosystem as well as goods and services. The users of the ecosystem obtain extended financial, information and social accessibility, higher speed of transactions, effectiveness of decision making and lower transaction costs. The partners providing third-party applications and services obtain an expanded client base and increased market for trading goods and services.

The principle of openness derives from the abovementioned principles of ecosystem and implies the opportunity of its integration with other services, digital products, data bases. In practice digital ecosystem can be closed as well with limited functionality and number of participants. The more open is the ecosystem the more opportunities it has for development including global scale.

The principle of ecosystem's flexibility determines opportunities for meeting individual needs. The essence of digital financial ecosystem implies personalization of services and meeting the needs of every actor. Every actor is unique and ecosystem constantly adjusts to specific needs. Moreover, modern society as well as institutional environment are permanently transformed that is why development of the ecosystem depends on its ability of fast adaptation to changing values, technologies, institutes.

The principle of distant identification is determined by the specifics of digital technologies enabling distant access to resources and interaction. Different identification methods can be used. At present the most popular ones are unique codes and access passwords, but in perspective the following methods will become popular: active using biometric data, telemetry, technologies of faces recognition with the help of artificial intelligence.

Principle of trust in digital environment is the basis for forming and developing a digital financial ecosystem. It is trust based on individual approach and effective system of security that creates competitive advantages and opportunities for developing a digital ecosystem. Long ago economists highlighted trust as a key factor in decision making $[11,12]$. The individual's trust to other participants of financial relations facilitates expanding new financial instruments, increasing speed and functionality of financial transactions by means of active usage of new financial technologies [13]. In the era of digital technologies new cost is created due to the trust and the last can be considered as a special currency.

The principle of simplicity is determined by human inherent motivation to minimize efforts aimed at reaching the intended effect. Simplicity of using a digital platform enables consumers to make research, compare and assess different variants of supply in the financial market. Due to it they find themselves in a more favourable position based on empirical knowledge. Simplifying financial relations including understandable financial services results in reducing risks and more effective control. [13, 14].

Digital financial ecosystem has a complex and dynamically developing structure. The compulsory elements of a digital financial ecosystem are presented in Figure 2.

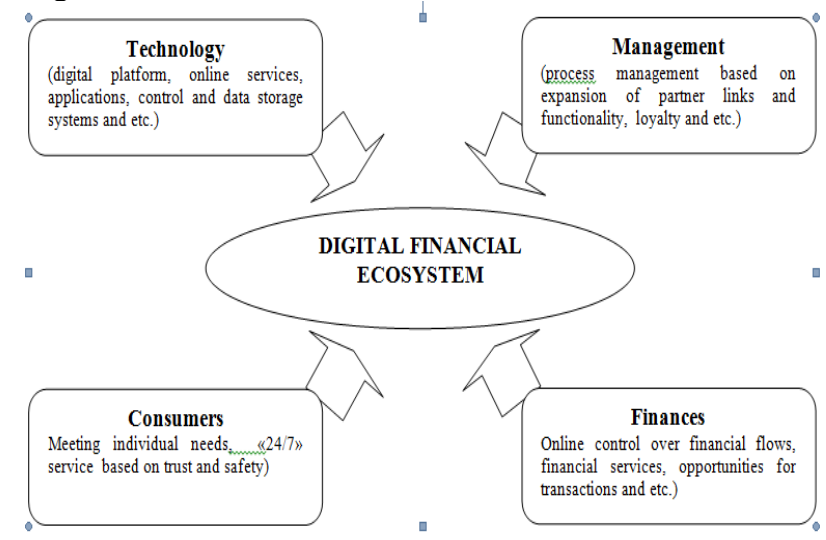

Fig. 2. Elements of digital financial ecosystem The source: provided by the authors.

In the contemporary world there are many digital financial ecosystems. Ecosystem as business model lay the foundation for the development of such companies Sber. Yandex, Apple, Amazon, Alibaba and others.

In the world market ecosystem of the group Alibaba is leading by the number of users. Created in 2003 [15] payment service of Alibaba company Alipay for payment in industrial e-commerce at present has over 1 billion users all over the world and continues its international expansion [16]. To the Kapron, Z. [17] this company that has changed the character of retail consumption in China can take on a global market of digital payments [17]. The peculiarity of development of the ecosystem of Alibaba Group is the inflow of users due to world expansion of e-commerce platforms. The basis of this ecosystem is a world famous service of mobile payments Alipay which includes opportunities of paying for purchases, money transfers, communal payments including payments by QR-code. The directions of development of Alibaba Group is on the one hand are connected with broadening its functionality by means of providing a full range of financial services, mobile system of organizing medical aid, charity projects in which participants can follow how their money was used and other applications. On the other hand the ecosystem of Alibaba is developing due to technical innovations such as the system of detecting images with the help of artificial intelligence which enables to evaluate the damage of the car, the cost of car repairmen and provide information about the nearest automobile service centers and the cost of their services with the help of photo send to the insurance agent [16].

By the diversity of its key spheres including telecommunications, financial services, FoodTech, ecommerce telemedicine, education, transport, cloud services, media and entertainments, estate, IT-services, analytics and others. The prominence can be given to 
Russian ecosystem Sber, However, this ecosystem doesn't have a unified digital platform at the moment (“one-stop-shop approach" doesn't work). Many consumers even don't know that DocDoc, Delivery, Okko, Citymobil, Domclick are elements of one ecosystem, and Sberb should still work in this direction.

The whole complex of digital financial ecosystems functioning in the country makes up the national digital financial ecosystem. In Russia further development of this sphere will be connected with active development of ecosystems of public organizations. (governmental authorities) as well as with increasing competitiveness of private ecosystems. The positive examples of public ecosystems are the "Portal of State Services" and the system of quick payments of the Bank of Russia. In order to expand payment transactions the Bank of Russia announced its decision to issue national currency in digital form - digital ruble [18]. It proves the increasing activity of the public sector in the digital environment.

Private digital financial ecosystems functioning in Russia can be divided into universal and niche. Forming universal ecosystems is aimed at providing consumer with a whole range of services for meeting existing and potential needs in one application. Yandex, Tinkoff can be referred to such ecosystems. Niche ecosystems develop a definite range of functions necessary for a particular group of consumers or for a particular sphere of activity. For instance, AlfaBank creates an ecosystem for representatives of small and medium business, Rosbank has concentrated its efforts on the perspective in their opinion niche - buying residential estate, Rosselkhozbank made a presentation of the ecosystem for farmers. Private ecosystems are created in order to attract the consumer and to make additional profit as well as to create entrance barriers for new participants.

In practice all ecosystems intersect, use external channels for promoting and rendering their services. Development of Russian national digital financial ecosystem will be based on generating the model of interaction of public and private ecosystems. There are at least two possible variants of interpenetration (Figure 3 ).

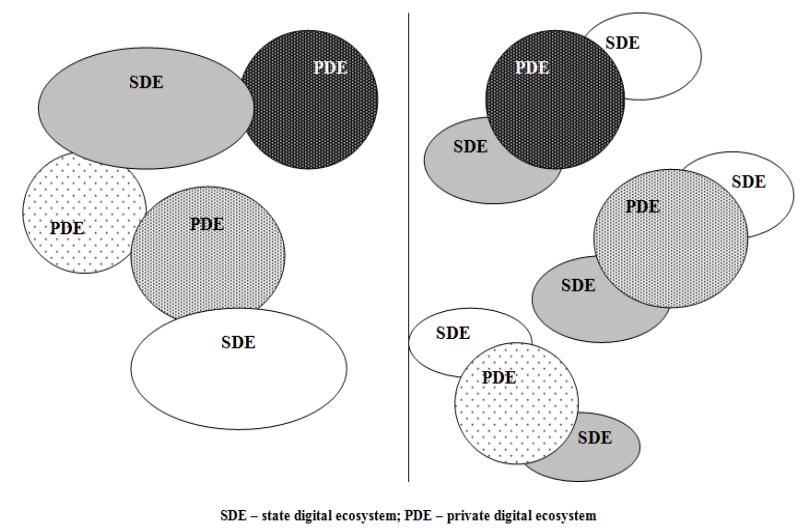

Fig. 3. Variants of development of national digital financial ecosystem

The source: Provided by the authors

The first variant implies autonomous functioning of state and private ecosystems with expanded functionality of them and different extent of interpenetration. At that state ecosystems will dominate in the sphere of public service. The advantages of this variant for state administration are that it saves the unity of the system of data in public sector, providing safety, control and managing BigData in public sector. However, in case of this approach state platforms will significantly stand behind private ecosystems by its functional and technological state. Besides, there will be duplicating of functions by a number of ecosystems [19].

The second variant is possible if ecosystems of state structures become applications of the largest private ecosystems. In this variant public services will be dissolved in the services of private ecosystems. The consumer will have an opportunity of receiving public services at any place and any time without leaving the private ecosystem. The main disadvantages of such variant are the loss of an unified channel of service and obtaining information as well as increasing information security risks.

As the world experience shows if the ecosystem is aimed at consumers values and interests it succeeds and develops permanently. If the digital financial ecosystem has the priority of fast accumulation of profit striving to increase the number of consumers at the expense of consumes' interests it has no potential for development and it doesn't facilitate financial accessibility and consequently development of economy and society as shows Kenya's experience [20].

Within the crisis caused by COVID-19 the advantages and opportunities of digital ecosystem only increase. Functional and technological specifics facilitate mitigating of negative consequences of social and economic crises caused by the pandemic as it gives an opportunity to solve urgent problems to use different services and purchase in social distancing [21]. In this respect the strategic priorities in development of Russian national financial ecosystem in conditions of a new reality are the following: (1) providing sufficient liquidity for market functioning and demand maintaining; (2) intensification of the exchange of information related to healthcare; (3) inclusive financing; (4) using digital channels for obtaining services and making payments for reducing contacts between people, and in case of necessity supporting people having no access to digital technologies; (5) directing financial resources to improve digital infrastructure in order to provide qualitative and permanent work of digital channels of communication.

\section{Conclusion}

Success and effectiveness of the Russian national digital financial ecosystem directly depend on new and productive forms of integration of public and private ecosystems for the benefit of consumers. Development of the digital ecosystem at the macrolevel increases economic stability and financial accessibility. Innovations in the sphere of digital finances have a longterm positive impact on financial market. Digital transactions increase transparency of economy reducing informal sector of economy, unofficial payments and 
circulation of false banknotes. Speed, simplicity and accessibility of financial services positively influence social welfare reducing the level of poverty and expanding opportunities for the realization of entrepreneurial initiative.

\section{References}

1. NAFI. Think Tank. Analytics and predictions. (2020), URL: https://nafi.ru/analytics/boleepoloviny-rossiyan-polzuyutsya-tsifrovymbankingom/ (date of access: 16.03.20)

2. RBC. Neobanks and lifetime-advisers: banking innovations of the nearest decades (2020), URL: https://trends.rbc.ru/trends/futurology/5f4d3aa99a79 4781e4b9ae68 (date of access: 16.03.20)

3. E. Fiyaksel, I. Sokolov, A. Solokhin, I. Kutepov, E. Privalova, E. Rozhkova, \& L. Lyakisheva Centre for Strategic research (2018), URL: https://publications.hse.ru/mirror/pubs/share/direct/2 19492205.pdf (date of access: 16.03.20)

4. Md. Hasan, Y. Morshadul, Lu, Khan, \& Shajib. Global Business Review (2020)

5. D. Salampasis, \& A.-L. MentionFinTech: Harnessing innovation for financial inclusion. In Handbook of blockchain, digital finance, and inclusion 1st ed., 2 (2018)

6. G-24. Fintech for financial inclusion: A framework for digital financial transformation. AFI Special Report. (2018), URL: https://www.g24.org/wpcontent/uploads/2018/09/G-24 (date of access: 16.03.20).

7. F. Guo, S. Kong \& J. Wang, China Economic Journal 9(3), 253-271 (2016)

8. S. Dubinin, Economic theory 21 (4) 6-11 (2017)

9. S. Bose, G. Dong, \& A. Simpson, The Financial Ecosystem. Palgrave Studies in Impact Finance 1, 19-46 (2019)

10. V. Slepov, S. Bondareva, Finances and Credit 48 2-17 (2016)

11. J. Keynes, Sellection (Moscow: Eksmo 2007)

12. F. Fukuyama, Trust: social moral virtues and the way to prosperity (Moscow, 2004)

13. V. Slepov, \& S. Bondareva, Personal finances: textbook / edited by prof. (Magistr: INFRA-M Moscow, 2019).

14. R. Feniks, Financial services: reloding (Ivanov and Ferber, Mann, 2012)

15. Vedomosti. How Alibaba designed a model of smart business.

URL: https://www.vedomosti.ru/management/articles/201 8/11/01/785430-alibaba (2018) (date of access: 16.03.20).
16. Z. Kapron, Journal of Payments Strategy and Systems 12, 68-73 (2018)

17. Bank of RussiaReport for public consulting "Digital ruble" (2020), URL: https://cbr.ru/eng/analytics/consultation-paper/theconsultation-paper-a-digital-ruble/ (date of access: 16.03.20).

18. O. Peterson, Research and Business Development Department 18, 329-340 (2018)

19. Q. Wang, Y. Jinbao, Chiu Yung-ho \& Lin Tai-Yu. Managerial and Decision Economics 41 (7) 12251236 (2020).

20. D. Arner, J. Barberis, J. Walker, R. Buckley, \& D. Zetzsche, Digital Finance \& Crisis. SSRN Electronic Journal, 17 (2020) 